\title{
Perbandingan Nilai Akurasi Algoritma Smoothing pada Mesin Penerjemah Statistik Bahasa Indonesia ke Bahasa Melayu Sambas dengan Language Model Toolkit IRSTLM
}

\author{
Ronja $^{\# 1}$, Herry Sujaini ${ }^{\# 2}$, Rudy Dwi Nyoto ${ }^{\# 3}$ \\ "Program Studi Informatika, Fakultas Teknik, Universitas Tanjungpura \\ Jl.Prof. Dr.H.Hadari Nawawi, Pontianak, 78124 \\ ${ }^{1}$ ronjaestudent.untan.ac.id \\ ${ }^{2}$ hseuntan.ac.id \\ ${ }^{3}$ rudydneinformatika.untan.ac.id
}

\begin{abstract}
Abstrak-Komunikasi merupakan bagian penting dalam berkehidupan sosial. Ketidakmampuan dalam berkomunikasi dapat menyebabkan tidak tersampaikannya suatu informasi serta terjadinya kesalahpahaman. Indonesia yang memiliki beragam suku dan budaya tidak dapat dipungkiri akan melahirkan interaksi antar suku yang mempunyai keunikan bahasa masing-masing. Mesin penerjemah statistik hadir sebagai salah satu solusi. Mesin penerjemah statistik pada penelitian ini menggunakan language model toolkit IRSTLM dengan bahasa Indonesia dan bahasa Melayu Sambas dengan data sebanyak 2700 baris kalimat korpus paralel. Algoritma smoothing merupakan komponen yang dapat meningkatkan akurasi hasil terjemahan pada mesin penerjemah. Perlunya dilakukan penelitian terhadap algoritma smoothing untuk mengetahui algortima smoothing dengan nilai BLEU score dan hasil terjemahan terbaik. Proses pengujian dilakukan dengan membandingkan nilai BLEU score dari masing-masing algoritma smoothing menggunakan metode penambahan secara konsisten pada setiap mesin menggunakan 200 korpus sebanyak sepuluh kali pengujian. Algoritma smoothing yang digunakan witten-bell, back-off, kneser-ney dan modified kneser-ney dan hasil yang didapat untuk algoritma smoothing terbaik yaitu modified kneser-ney dengan nilai $68,04 \%$ menggunakan 3gram dan $67,8 \%$ menggunakan 5gram. Pada pengujian manual dilakukan terlebih dahulu mencari nilai BLEU score terbaik menggunakan metode k-fold cross validation dengan algoritma smoothing modified kneser-ney hasil yang didapat yaitu dengan nilai BLEU score tertinggi sebesar $84,18 \%$. Data yang digunakan pada mesin tersebut dijadikan bahan untuk pengujian manual oleh dua orang ahli bahasa dengan nilai akurasi $94,87 \%$ dan $96,65 \%$.
\end{abstract}

Kata kunci - Bahasa Indonesia, Bahasa Melayu Sambas, Mesin Penerjemah Statistik, IRSTLM, Algoritma Smoothing.

\section{PENDAhUluan}

Bahasa merupakan alat komunikasi yang digunakan oleh manusia untuk berinteraksi dan bertukar informasi sesama manusia. Dengan adanya bahasa, seseorang dapat berinteraksi dengan lingkungan sekitar dan mengetahui informasi yang dibutuhkan. Sebagaimana yang kita ketahui bahwa di Indonesia terdiri dari berbagai macam suku dan budaya, ini berbanding lurus dengan keberagaman bahasa yang dimiliki oleh bangsa Indonesia. Terdapat sekitar 724 bahasa daerah yang tersebar di seluruh pelosok Negeri ini. Setiap daerah pasti mempunyai keunikan tersendiri terkait bahasa mereka[1].

Dengan beragamnya bahasa daerah yang ada di Indonesia tidak mungkin untuk dikuasai secara keseluruhan. Setiap bahasa daerah memiliki ciri khas atau karakteristik tersendiri, tidak terkecuali dengan bahasa Melayu Sambas. Bahasa Melayu Sambas memiliki beberapa ciri khas di antaranya: penyebutan huruf "E" seperti bunyi penyebutan pada kata "LELE", misalnya pada kata "kau na' ngape ?". Ciri khas lainnya dari bahasa Melayu Sambas yaitu pada pengucapan huruf ganda pada kata tertentu misalnya "BALLIK" contoh katanya "ballik udek hari udah malam"'[2]. Atas hal tersebut, bahasa Melayu Sambas dipilih untuk dijadikan mesin penerjemah agar dapat membantu masyarakat memahami bahasa Melayu Sambas serta agar hasil penerjemahan yang dihasilkan memiliki tingkat akurasi yang baik.

Mesin penerjemah merupakan alat penerjemah otomatis pada sebuah teks dari satu bahasa sumber ke bahasa target[3]. Mesin penerjemah memiliki keterbatasan dalam menerjemahkan suatu teks bahasa, sehingga dapat menyebabkan berkurang atau bahkan merubah arti dan maksud dari suatu kalimat. Ada beberapa cara yang dapat diterapkan agar dapat mengoptimalkan hasil dari mesin penerjemah salah satunya dengan pendekatan mesin 
penerjemah statistik atau Statistical Machine Translation. Mesin penerjemah statistik adalah sebuah pendekatan mesin penerjemah dengan hasil terjemahan.

Dalam penyusunan mesin penerjemah statistik diperlukan salah satu komponen yang harus ada yaitu model bahasa (Language Model) dan translasi model (Translasi Model). Model bahasa merupakan model yang digunakan untuk menentukan kesesuaian suatu kata, frasa, atau kalimat dalam bahasa tertentu. Dan termasuk juga persentase kemunculan kalimat yang diterjemahkan juga ditentukan oleh model bahasa. Translasi model yang berfungsi untuk Menyelaraskan korpus yang disiapkan mempertimbangkan struktur kedua bahasa. Tools Mgiza digunakan untuk perataan tingkat kata, perataan multibahasa yang digunakan untuk perataan tingkat frasa dan perataan tingkat kalimat[4]. Penelitian terkait yaitu pada penelitian dengan judul "Assamese-English Bilingual Machine Translation" [5]. Pada penelitian ini dilakukan dengan model IRSTLM didapatkan hasil akurasi mesin penerjemah dari bahasa Assamese ke bahasa Inggris sebesar 9,72\% dan bahasa Inggris ke bahasa Assamese sebesar 5,02\%. Dan juga pada penelitian lain yaitu pada penelitian Wenyang Zhang [6] dengan judul "Comparing the Effect of Smoothing and Order of N-gram for Language Model : Find the Best Way to Combine the Smoothing and Order of N-gram" Pada penelitian ini dilakukan perbandingan Algoritma Smoothing : Simple N-gram, Interpolation, Good Turing Discounting, Natural Discounting, Witten-Bell Discounting, Modified Kneserney Discounting \& Original Kneser-ney Discounting pada model bahasa SRILM, dengan melakukan percocokan antara Algoritma Smoothing dan penggunaan jumlah $\mathrm{N}$ gram. Dengan hasil percobaan pertama dimana pencocokan terbaik adalah Witten-Bell Discounting dan 3 gram dengan hasil perplexity 311.097, percobaan kedua yang paling cocok adalah Witten-Bell Discounting dan 5gram dengan hasil perplexity 45.9748.

Model bahasa $\mathrm{N}$-gram menggunakan asumsi Markov untuk memutuskan probabilitas kalimat menjadi nilai probabilitas masing-masing kata, mengingat (terbatas) jumlah kata-kata sebelumnya. Model bahasa dioptimalkan pada kebingungan, ukuran yang terkait dengan seberapa besar probabilitas diberikan ke satu set teks model bahasa yang sebenarnya.[7] Tantangan mendasar dalam model bahasa adalah menangani jarangnya data tersebut. Hanya karena sesuatu belum terlihat dalam teks pelatihan, bukan berarti tidak mungkin [7]. Pada pemodelan bahasa oleh $N$ gram sering ditemukan kata-kata dengan kombinasi yang tidak terobservasi selama pelatihan model tersebut sehingga secara otomatis probabilitas deretan kata ini menjadi nol. Probabilitas nol dari suatu bigram atau $N$ gram akan mengakibatkan probabilitas nol dari kalimat dimana bigram tersebut berada. Salah satu teknik yang dapat digunakan agar model bahasa tidak memberikan probabilitas nol untuk peristiwa yang tak terlihat ini adalah melakukan subsidi silang probabilitas. Pendekatan ini dinamakan smoothing (memperlancar) atau discounting (pengurangan). Nama smoothing berasal dari fakta bahwa teknik ini cenderung membuat distribusi lebih seragam, dengan menyesuaikan probabilitas rendah seperti probabilitas nol ke atas, dan probabilitas tinggi ke bawah. Tidak hanya metode penghalusan umumnya mencegah nilai probabilitas nol, tetapi metode ini juga berusaha untuk meningkatkan akurasi model secara keseluruhan. Kapanpun probabilitas diperkirakan dari beberapa hitungan, pemulusan berpotensi meningkat secara signifikan perkiraan [8].

Nilai akurasi merupakan hal yang sangat penting untuk diperhatikan dalam mesin penerjemah statistik. Tingkat kesesuaian penerjemahan bahasa sumber dengan arti sesungguhnya dalam bahasa target dilihat dari nilai akurasi yang dihasilkan.

Berdasarkan penjelasan yang sudah dipaparkan, penelitian ini akan membuat mesin penerjemah statistik dengan jenis model bahasa IRSTLM (Institute Ricerca Scientifica e Tecnologica Language Model) dengan membandingkan algoritma smoothing, antara lain Back-off, Witten-Bell (defaulf), Kneser-Ney \& Modified KneserNey dari keempat algoritma smoothing tersebut algoritma mana yang lebih tepat dan akurasi paling tinggi dalam penerjemahan Bahasa Indonesia ke Bahasa Melayu Sambas berdasarkan evaluasi otomatis BLEU (bilingual evaluation understudy) dan pengujian oleh ahli Bahasa.

\section{LANDASAN TEORI}

IRSTLM merupakan open source library yang dapat membuat, menyimpan, dan mengakses model bahasa (Language model) dalam skala yang luas dengan perangkat keras konvensional. Library menyediakan skrip training untuk mendistribusikan training model bahasa (Language model) dengan cluster komputer melalui manajer antrian standar. Model bahasa (Language model) disimpan dalam format ARPA konvensional, dapat dikompilasi lebih lanjut ke dalam format biner untuk mempercepat loading time, probabilitas $\mathrm{N}$-gram dapat dikuantisasi untuk menghemat ruang lebih lanjut, dan pada akhirnya model bahasa (Language model) dapat diakses dari disk melalui pemetaan memori, menghasilkan pengurangan kebutuhan memori dengan time cost yang sangat wajar [9].

IRSTLM dalam proses pemodelan bahasa (Language model) melalui beberapa proses secara umum proses yang dilalui adalah pembentukan pemodelan bahasa dan probabilitas dari pemodelan bahasa[10]. Language Model untuk hal ini jenis language model toolkit memiliki kesamaan yaitu pada proses pemodelan bahasa dan perhitungan probabilitas korpus dari pemodelan bahasa adapun perbedaan yang terdapat di beberapa jenis language model toolkit adalah pada algoritma smoothing yang bertujuan agar memiliki kualitas estimasi yang baik terhadap language model sehingga tidak ada lagi probabilitas dari korpus yang ditraining bernilai 0 . Algoritma smoothing yang disupport oleh IRSTLM adalah sebagai berikut:

1) Back-off

2) Witten-Bell (Default) 
3) Kneser-Ney

4) Modified Kneser-Ney

A. Back-off

Interpolasi merupakan metode yang mudah dimengerti dan diterapkan. Ada beberapa algoritma yang lebih baik, seperti Back-off pemodelan N-gram. Menggunakan GoodTuring discounting berdasarkan algoritma Katz dan biasa dikenal dengan sebutan algoritma Katz Backoff [6] dapat dilhat pada persamaan dibawah ini.

$$
\begin{aligned}
& p_{\text {katz }}\left(w_{n} \mid w_{n-N+1}^{n-1}\right)= \\
& \left\{\begin{aligned}
P^{*}\left(w_{n} \mid w_{n-N+1}^{n-1}\right) & \text { if } C\left(w_{n-N+1}^{n}\right)>0 \\
\alpha\left(w_{n} \mid w_{n-N+1}^{n-1}\right) P_{\text {katz }}\left(w_{n} \mid w_{n-N+2}^{n-1}\right) & \text { otherwise }
\end{aligned}\right.
\end{aligned}
$$

\section{B. Witten-Bell (Default)}

Bell, Cleary, Witten dalam [8] Witten-Bell smoothing dikembangkan dengan tugas untuk memadatkan suatu teks, dan dapat dipertimbangkan sebagai Jelinek-Mercer smoothing praktis dapat dilihat pada persamaan dibawah ini.

$$
1-\lambda_{w_{i-n+1}^{i-1}}=\frac{N_{1}+\left(w_{i-n+1}^{i-1} \cdot\right)}{N_{1}+\left(w_{i-n+1}^{i-1} \cdot\right)+\sum_{w_{i}}\left(c_{i-n+1}^{i}\right)}
$$

\section{Kneser-Ney}

Kneser dan Ney dalam Chen \& Goodman[8], telah memperkenalkan sebuah terobosan positif untuk algoritma discounting, dimana distribusi lower-order digabungkan distribusi high-order yang dibangun dengan cara yang baru. Pada algoritma sebelumnya, distribusi lower-order umumnya dianggap versi yang lebih halus dari distribusi lower-order maximum likehood. Namun, distribusi lowerorder adalah faktor signifikan dalam gabungan yang dimana didalamnya hanya sedikit atau tidak ada perhitungan yang disajikan distribusi high-order. Akibatnya harus dioptimalkan agar memiliki kinerja yang baik dalam situasi ini. Faktanya, pada Kneser-Ney smoothing probabilitas unigram dalam model bigram dihitung dengan cara ini. Perhitungan pada paper ini berbeda dengan paper aslinya.

Disini, disajikan distribusi yang berbeda dari distribusi yang dihasilkan daripada distribusi yang disajikan oleh Kneser-Ney [11]. Diasumsikan bahwa model memiliki bentuk yang diberikan dalam persamaan [8]

$$
\begin{aligned}
& p_{K N}\left(w_{i} \mid w_{i-n+1}^{i-1}\right)=\frac{\max \left\{c\left(w_{i-n+1}^{i}\right)-D, 0\right\}}{\sum_{w_{i}} c\left(w_{i-n+1}^{i}\right)}+\frac{D}{\sum_{w_{i}} c\left(w_{i-n+1}^{i}\right)} N_{1}+ \\
& \left(w_{i-n+1}^{i-1} \bullet\right) p_{K N}\left(w_{i} \mid w_{i-n+2}^{i-1}\right)
\end{aligned}
$$

Adapun persamaan diatas adalah persamaan yang berlawanan dengan yang ada di paper yang asli pada persamaan dibawah.

$$
\begin{aligned}
& p_{K N}\left(w_{i} \mid w_{i-n+1}^{i-1}\right)= \\
& \left\{\begin{array}{cc}
\frac{\max \left\{c\left(w_{i-n+1}^{i}\right)-D, 0\right\}}{\sum_{w_{i}} c\left(w_{i-n+1}^{i}\right)} & \text { if } c\left(w_{i-n+1}^{i-1}\right)>0 \\
\gamma\left(w_{i-n+1}^{i-1}\right) p_{K N}\left(w_{i} \mid w_{i-n+2}^{i-1}\right) & \text { if } c\left(w_{i-n+1}^{i-1}\right)=0
\end{array}\right.
\end{aligned}
$$

Dimana $\gamma\left(\mathrm{w} \_(\mathrm{i}-\mathrm{n}+1)^{\wedge}(\mathrm{i}-1)\right)$, dipilih untuk menghasilkan jumlah distribusi menjadi 1. Jadi, interpolasi dilakukan dengan distribusi lower-order, tidak hanya dilakukan dengan kata-kata yang memiliki nilai 0 dalam distribusi higher-order. [8]

\section{Modified Kneser-Ney}

Modified Kneser-Ney ditemukan oleh dua orang penemu bernama Stanley F. Chen dan Joshua Goodman pada tahun 1998, yang membedakan algoritma Kneser-Ney dengan Modified Kneser-Ney adalah pada penggunaan variable discount D. Pada algoritma Kneser-Ney untuk semua jumlah probabilitas bukan nol dinyatakan dalam discount D, sedangkan pada Modified Kneser-Ney terdapat tiga jenis parameter D yaitu D1, D2, dan D3+, yang diaplikasikan menjadi $N$-gram dengan, satu, dua, dan tiga atau bahkan lebih dengan masing-masing perhitungannya dalam persamaan dibawah.

$$
\begin{aligned}
& p_{K N}\left(w_{i} \mid w_{i-n+1}^{i-1}\right)=\frac{c\left(w_{i-n+1}^{i}\right)-D\left(c\left(w_{i-n+1}^{i}\right)\right)}{\sum_{w_{i}} c\left(w_{i-n+1}^{i}\right)}+ \\
& \gamma\left(w_{i-n+1}^{i-1}\right) p_{K N}\left(w_{i} \mid w_{i-n+2}^{i-1}\right)
\end{aligned}
$$

Dimana :

$$
\left\{\begin{array}{cl}
0 & \text { if } c=0 \\
D_{1} & \text { if } c=1 \\
D_{2} & \text { if } c=2 \\
D_{3} & \text { if } c=3
\end{array}\right.
$$

\section{Metode PenElitian}

Penelitian dilakukan dengan langkah-langkah sistematis, sesuai pada Gambar. 1. 


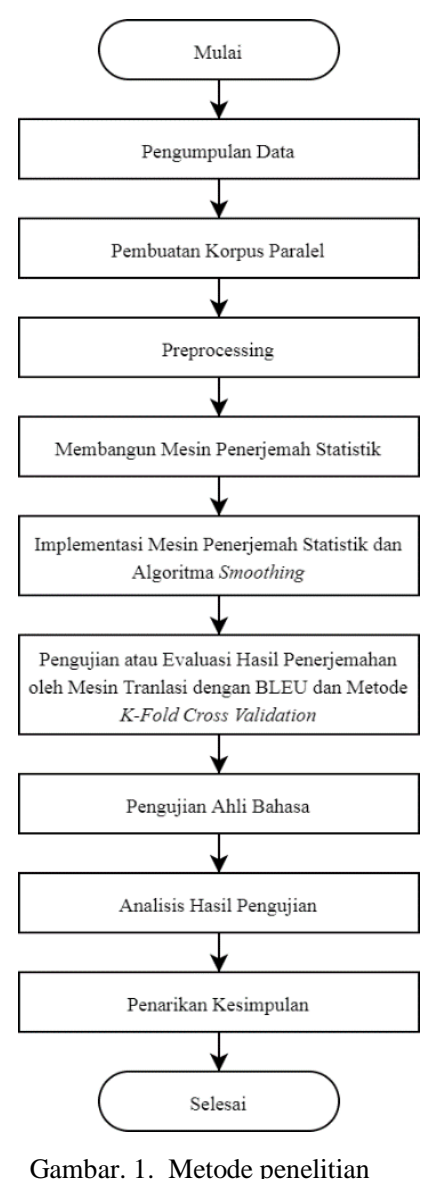

\section{A. Pengumpulan Data}

Untuk mengumpulkan data metode yang digunakan yaitu wawancara dan observasi. Langkah-langkah yang dilakukan adalah sebagai berikut.

1) Wawancara: Diperlukan ahli bahasa sebagai narasumber dalam pengujian hasil translasi mesin penerjemah pada penelitian ini. Penulis melakukan wawancara kepada saudara Hary, S.Pd yang merupakan lulusan pendidikan bahasa Indonesia dan Sandra, S.Pd. Mereka berdua berasal dari kabupaten Sambas yang akan menjadi ahli bahasa dengan cara berdiskusi sejauh mana mereka mengerti bahasa Melayu Sambas dan kesediaan mereka untuk menjadi ahli bahasa dalam penelitian ini.

2) Observasi: Mencari dokumen-dokumen bahasa Indonesia yang nantinya akan diserahkan kepada ahli bahasa untuk diterjemahkan ke dalam bahasa Melayu Sambas yang akan dijadikan korpus dalam penelitian, yaitu korpus bahasa Indonesia dan korpus bahasa Melayu Sambas.

\section{B. Pembuatan Korpus Paralel}

Korpus merupakan kumpulan dari beberapa teks sebagai sumber penelitian bahasa dan sastra. Penelitian yang akan dilakukan terdapat dua buah korpus paralel atau bisa disebut korpus bilingual dari dua bahasa yang berbeda [12] yang digunakan yaitu korpus bahasa Indonesia dan korpus bahasa Melayu Sambas. Adapun korpus paralel pada penelitian ini berupa dokumen-dokumen bahasa Indonesia yang kemudian diterjemahkan ke dalam bahasa Melayu Sambas. Korpus paralel yang digunakan disimpan dengan nama yang sama, tetapi berbeda format berkasnya. Korpus paralel yang dibuat dalam bentuk file teks disimpan dengan format .id untuk bahasa Indonesia dan .sb untuk bahasa Melayu Sambas. Contoh korpus paralel yang dibuat dalam bentuk file teks dapat dilihat pada

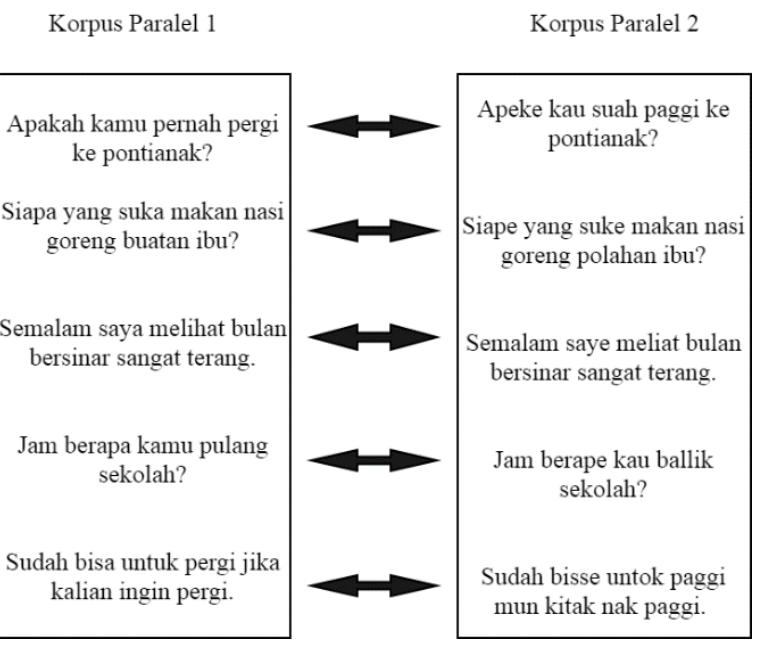

Gambar. 2. Korpus paralel

\section{Preprocessing}

Proses ini terdiri dari Case folding yang merupakan tahapan mengubah huruf dalam dokumen menjadi huruf kecil. Karakter selain huruf dihilangkan dan dianggap pembatas (delimiter)[13] dapat dilihat pada Gambar. 3. Dan tahap tokenizing adalah tahap pemotongan string input berdasarkan tiap kata yang menyusunnya [13] seperti pada Gambar. 4.

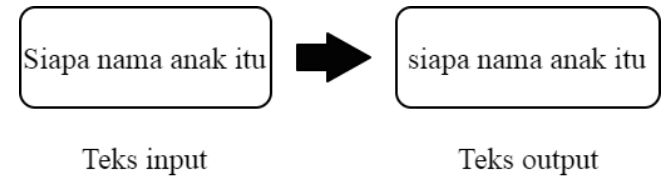

Gambar. 3. Case folding [13]

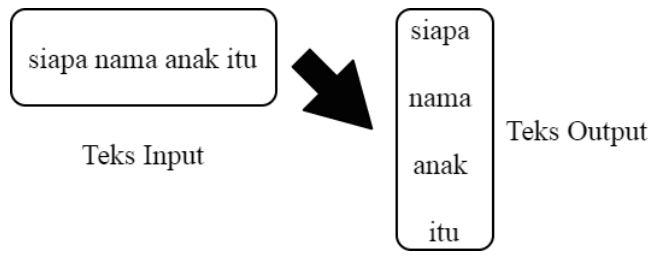

Gambar. 4. Tokenizing [13].

\section{Membangun Mesin Penerjemah Statistik}

Membangun mesin penerjemah statistik dilakukan dengan cara melakukan instalasi perangkat lunak. Adapun perangkat lunak yang akan di-install untuk membangun mesin penerjemah statistik adalah sebagai berikut.

1) Moses decoder untuk membangun mesin penerjemah. 
2) Mgiza untuk compile Moses.

3) IRSTLM untuk pemodelan bahasa.

4) BLEU untuk pengujian akurasi[14].

Seluruh perangkat lunak yang digunakan dalam membangun mesin penerjemah statistik merupakan perangkat lunak yang bersifat open source dan di-install pada system operasi Ubuntu.

E. Implem entasi Mesin Penerjemah Statistik dan Algoritma Smoothing

Arsitektur sistem pada penelitian ini terdiri dari beberapa proses pemodelan yaitu pemodelan bahasa, pemodelan translasi, decoding, dan evaluasi hasil terjemahan. Arsitektur sistem mesin penerjemah statistik ditunjukkan pada Gambar. 5.

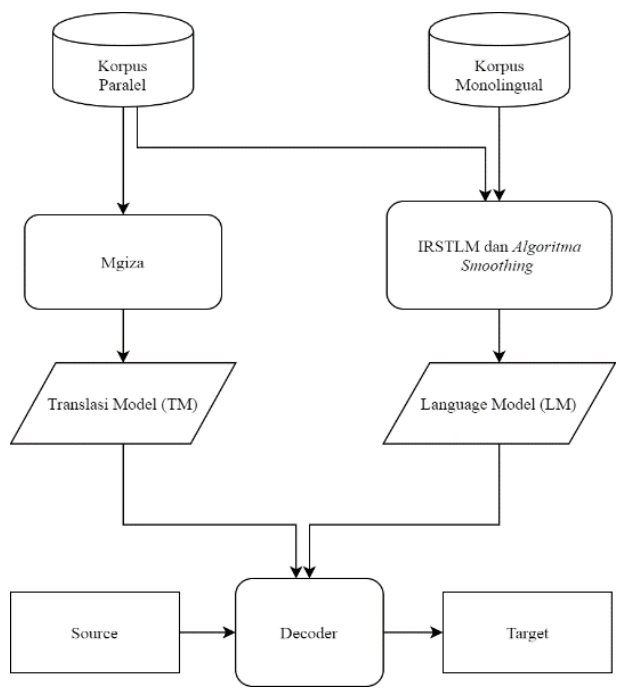

Gambar. 5. Arsitektur sistem mesin penerjemah [15]

Korpus paralel dalam file teks terdiri dari dua buah korpus yaitu korpus bahasa Indonesia dan korpus bahasa Melayu Sambas. Mesin penerjemah dibangun dengan korpus paralel, dimana korpus paralel akan dilakukan translasi model menggunakan tools Mgiza yang menghasilkan translation model, korpus paralel tersebut dipecah menjadi korpus monolingual dimana korpus monolingual tersebut dilakukan proses language model atau pemodelan bahasa menggunakan IRSTLM dengan algoritma smoothing yang digunakan yang akan menghasilkan language model bahasa target, Proses selanjutnya yaitu Translation Model (bahasa sumber) dan Language Model (bahasa target) yang dimana bahasa sumber dan bahasa target tersebut dilakukan proses dicoding menggunakan decoder untuk mendapatkan hasil terjemahan dari input bahasa yang ingin diterjemahkan dan menghasilkan terjemahan berupa bahasa target.

Pemodelan bahasa oleh IRSTLM (IRST Language Model) dilakukan pada bahasa target dan menghasilkan tabel model bahasa dengan n-gram data. Model bahasa ngram memiliki nilai probabilitas dalam bahasa target. Proses pemodelan bahasa oleh IRSTLM dapat dilihat pada Gambar. 6.

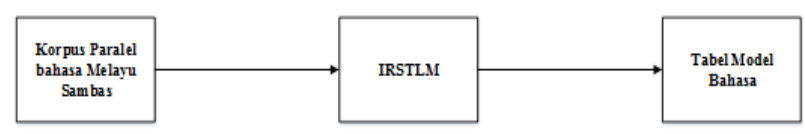

Gambar. 6. Proses pemodelan bahasa menggunakan language model toolkit IRSTLM [2]

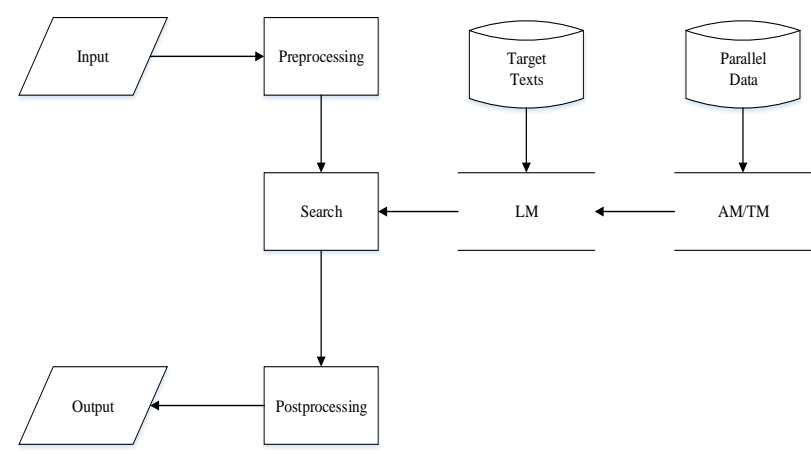

Gambar. 7. Arsitektur sistem mesin penerjemah language model toolkit IRSTLM [16]

Adapun untuk pemrosesan model bahasa pada jenis language model toolkit IRSTLM seperti terlihat pada Gambar . 7. sama dengan penjelasan pemrosesan model bahasa pada umumnya yaitu diawali dengan proses $N$-gram Modelling, lalu N-gram Probabilities, Discount Methods \& Frequency Smoothing, dan ARPA File / Binary File.

$N$-gram Modelling merupakan proses menentukan berapa banyak $N$-gram yang diinginkan dalam suatu pemodelan bahasa atau berapa banyak penggalan kata ataupun karakter yang diinginkan dalam pembuatan pemodelan bahasa. Cara mengatur jumlah $\mathrm{N}$-gram dilakukan pada saat training dengan menambahkan script order diketik pada script, “. . . - o 5 ...” seperti menandakan berarti jumlah pembagian $N$-gram hanya 5 buah seperti terlihat pada Gambar. 8 .

Idatal
ngram 1 $=13238$
ngram $2=50460$
ngram $3=66643$
ngram $4=70692$
ngram $5=72081$
Gambar $8 . N$ - gram modelling

$N$-gram Probabilities merupakan proses untuk menghitung setiap kemungkinan atau probabilitas kemunculan kata atau karakter pada korpus seperti terlihat pada Gambar. 9. 


\begin{tabular}{l} 
11-grams: \\
-3.954363 muncol -0.301030 \\
-4.255393 kekhawateran -0.301030 \\
-3.380332 secare -0.380211 \\
-3.109265 luas -0.511883 \\
\hline 2 -grams: \\
-0.778151 muncol kekhawateran -0.301030 \\
-0.778151 muncol di -0.301030 \\
-0.778151 muncol sebagai -0.301030 \\
-0.301030 kekhawateran secare -0.301030 \\
-9 \\
13-grams: \\
-0.301030 muncol kekhawateran secare \\
-0.301030 muncol di old \\
-0.301030 muncol sebagai kuda \\
-0.301030 kekhawateran secare luas \\
\hline \hline
\end{tabular}

Gambar. 9. N-gram probabilities dari korpus paralel bahasa melayu sambas

Discount Methods \& Frequency Smoothing digunakan untuk meminimalisir bahkan menghilangkan probabilitas bernilai "0" pada pemodelan bahasa pada Gambar. 10 .

\begin{tabular}{|l||l|l|l|l|l|l|l|l|}
\hline & $\mathrm{i}$ & want & to & eat & chinese & food & lunch & spend \\
\hline \hline $\mathrm{i}$ & 5 & 827 & 0 & 9 & 0 & 0 & 0 & 2 \\
want & 2 & 0 & 608 & 1 & 6 & 6 & 5 & 1 \\
to & 2 & 0 & 4 & 686 & 2 & 0 & 6 & 211 \\
eat & 0 & 0 & 2 & 0 & 16 & 2 & 42 & 0 \\
chinese & 1 & 0 & 0 & 0 & 0 & 82 & 1 & 0 \\
food & 15 & 0 & 15 & 0 & 1 & 4 & 0 & 0 \\
lunch & 2 & 0 & 0 & 0 & 0 & 1 & 0 & 0 \\
spend & 1 & 0 & 1 & 0 & 0 & 0 & 0 & 0 \\
\hline \hline
\end{tabular}

Gambar. 10. Tabel probabilitas model bahasa sebelum dilakukan discounting methods \& frequency smoothing [17]

Setelah itu sebagai contoh dengan digunakan Laplacesmoothing untuk memunculkan probabilitas yang bernilai "0" tadi dengan menggunakan persamaan dibawah.

$$
\begin{aligned}
& P^{*}\left(w_{n} \mid w_{n-1}\right)=\frac{C\left(w_{n-1} w_{n}\right)+1}{C\left(w_{n-1}\right)+V} \\
& c^{*}\left(w_{n-1} w_{n}\right)=\frac{\left[C\left(w_{n-1} w_{n}\right)+1\right] \times C\left(w_{n-1}\right)}{C\left(w_{n-1}\right)+V}
\end{aligned}
$$

Pada Akhirnya barulah didapatkan hasil dari probabilitas yang semuanya memiliki nilai tanpa terkecuali dilihat pada Gambar . 11.

\begin{tabular}{|l||l|l|l|l|l|l|l|l|}
\hline & $\mathrm{i}$ & want & to & eat & chinese & food & lunch & spend \\
\hline \hline $\mathrm{i}$ & 3.8 & $\mathbf{5 2 7}$ & 0.64 & 6.4 & 0.64 & 0.64 & 0.64 & 1.9 \\
want & 1.2 & 0.39 & 238 & 0.78 & 2.7 & 2.7 & 2.3 & 0.78 \\
to & 1.9 & 0.63 & 3.1 & 430 & 1.9 & 0.63 & 4.4 & 133 \\
eat & 0.34 & 0.34 & 1 & 0.34 & 5.8 & 1 & 15 & 0.34 \\
chinese & 0.2 & 0.098 & 0.098 & 0.098 & 0.098 & 8.2 & 0.2 & 0.098 \\
food & 6.9 & 0.43 & 6.9 & 0.43 & 0.86 & 2.2 & 0.43 & 0.43 \\
lunch & 0.57 & 0.19 & 0.19 & 0.19 & 0.19 & 0.38 & 0.19 & 0.19 \\
spend & 0.32 & 0.16 & 0.32 & 0.16 & 0.16 & 0.16 & 0.16 & 0.16 \\
\hline
\end{tabular}

Gambar. 11. Tabel probabilitas model bahasa sesudah dilakukan discounting methods \& frequency smoothing

File yang telah diproses sedemikian rupa setelah melewati tahap $N$-gram Modelling, $N$-gram Probabilities, Discount Methods \& Frequency Smoothing sehingga siap untuk diproses pada pemodelan translasi untuk membangun mesin penerjemah statistik. Adapun contoh format ARPA file dapat dilihat pada Gambar. 12.

\begin{tabular}{|l|}
\hline iARPA \\
idatal \\
ngram $1=22$ \\
ngram $2=32$ \\
ngram $3=31$ \\
11-grams: \\
-1.249669 this -0.698970 \\
-1.409369 should -0.954243 \\
-1.409369 also -0.954243 \\
-0.901214 be -0.903090 \\
-1.041393 there -1.041393 \\
\hdashline 2 -grams: \\
-0.397940 this should -0.845098 \\
-0.477121 this we -0.778151 \\
-1.176091 this may 0.000000 \\
-0.051153 should also -0.954243 \\
-0.051153 also be -0.954243 \\
\hdashline $3-$-grams: \\
-0.066947 this should also \\
-0.079181 this we shall \\
-0.051153 should also be \\
-0.051153 also be there \\
-0.243038 be there is \\
\hdashline lend \\
\hline
\end{tabular}

Gambar. 12. Contoh tabel model bahasa menggunakan language model toolkit IRSTLM[9]

\section{F. Pengujian atau Evaluasi Hasil Mesin Penerjemahan oleh Mesin Translasi dengan BLEU dan Metode K-fold Cross Validation}

Pengujian dilakukan untuk mendapatkan nilai akurasi terjemahan mesin translasi. Pengujian dilakukan secara otomatis menggunakan BLEU. BLEU (Billingual Evaluation Understudy) mengukur modified n-gram precision score antara hasil terjemahan otomatis dengan terjemahan rujukan dan menggunakan konstanta yang disebut brevity penalty. Nilai BLEU didapat dari hasil dari modified precision score [18]. Gambar 13 dibawah ini merupakan contoh grafik hasil pengujian menggunakan 3 gram dan 5gram [6] dengan 10 kali percobaan dan penambahan jumlah korpus secara konstan yaitu 200 korpus. 


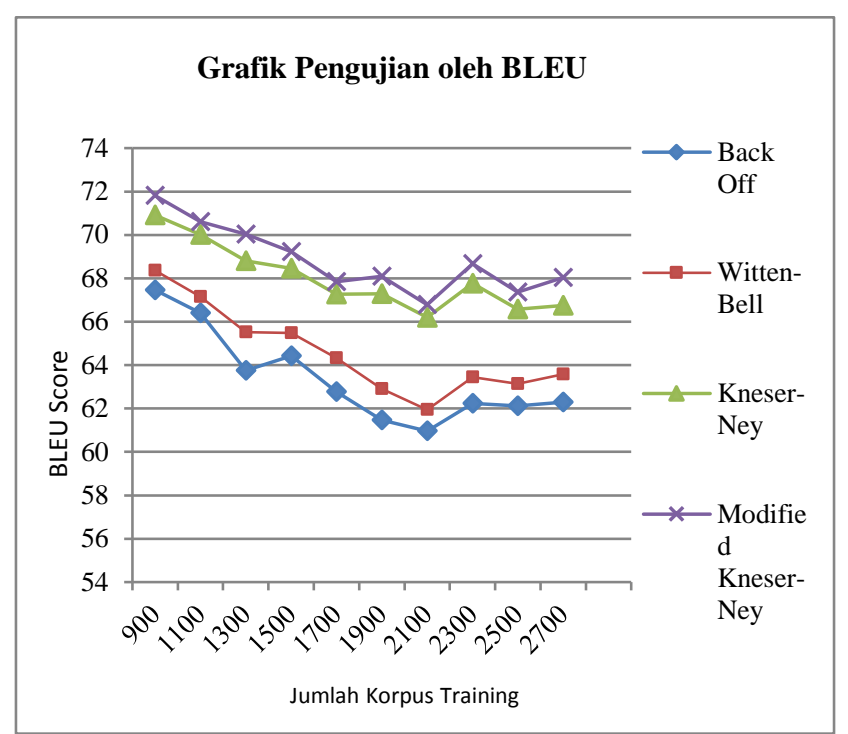

Gambar. 13. Grafik pengujian oleh BLEU

Dari pengujian otomatis menggunakan BLEU diatas diambil algoritma dengan nilai paling tinggi pada pengujian terakhir, seperti terlihat pada Gambar. 13. Nilai Score BLEU paling tinggi ada pada Modified Kneser-Ney dengan nilai $68,04 \%$ maka algoritma inilah yang akan digunakan pada metode $K$-Fold Cross Validation untuk memastikan keakuratan dari hasil uji[19]. Mesin penerjemah yang diuji berdasarkan jenis language model toolkit IRSTLM dan algoritma smoothing yang berbeda. Pada penelitian ini menggunakan total 2.700 kalimat korpus paralel bahasa Indonesia dan bahasa Melayu Sambas dengan format 270 kalimat uji dan 2.430 kalimat yang di-training.

\begin{tabular}{|l|l|l|l|l|l|l|l|l|l|}
\hline 1 & 2 & 3 & 4 & 5 & 6 & 7 & 8 & 9 & 10 \\
\hline 1 & 2 & 3 & 4 & 5 & 6 & 7 & 8 & 9 & 10 \\
\hline & & & & & & & & & \\
\hline 1 & 2 & 3 & 4 & 5 & 6 & 7 & 8 & 9 & 10 \\
\hline & & & & & & & & & \\
\hline 1 & 2 & 3 & 4 & 5 & 6 & 7 & 8 & 9 & 10 \\
\hline & & & & & & & & & \\
\hline 1 & 2 & 3 & 4 & 5 & 6 & 7 & 8 & 9 & 10 \\
\hline & & & & & & & & & \\
\hline 1 & 2 & 3 & 4 & 5 & 6 & 7 & 8 & 9 & 10 \\
\hline & & & & & & & & & \\
\hline 1 & 2 & 3 & 4 & 5 & 6 & 7 & 8 & 9 & 10 \\
\hline & & & & & & & & & \\
\hline 1 & 2 & 3 & 4 & 5 & 6 & 7 & 8 & 9 & 10 \\
\hline & & & & & & & & & \\
\hline 1 & 2 & 3 & 4 & 5 & 6 & 7 & 8 & 9 & 10 \\
\hline & & & & & & & & & \\
\hline 1 & 2 & 3 & 4 & 5 & 6 & 7 & 8 & 9 & 10 \\
\hline & & & & & & & & & \\
\hline & & & Data Pengujian & & & & \\
\hline & & & Data Pelatihan & & & & \\
\hline
\end{tabular}

Gambar. 14. Pengujian dengan metode $K$-fold cross validation
Gambar. 14. merupakan pengujian dengan metode $K$ Fold Cross Validation menggunakan 2.700 kalimat dimana dilakukan 10 kali percobaan dan per percobaan 270 kalimat sebagai korpus uji

Keterangan:

1. Data Uji $=$ Kalimat $1-270$

2. Data Uji $=$ Kalimat $271-540$

3. Data Uji $=$ Kalimat $541-810$

4. Data Uji $=$ Kalimat $811-1.080$

5. Data Uji $=$ Kalimat $1.081-1.350$

6. Data Uji $=$ Kalimat $1.351-1.620$

7. Data Uji $=$ Kalimat $1.621-1.890$

8. Data Uji $=$ Kalimat $1.891-2.160$

9. Data Uji $=$ Kalimat $2.161-2.430$

10. Data Uji $=$ Kalimat $2.431-2.700$

\section{G. Pengujian Ahli Bahasa}

Pengujian ahli bahasa dilakukan apabila telah dilakukan pengujian hasil evaluasi mesin penerjemah statistik dengan BLEU menggunakan metode K-Fold Cross Validation. Pengujian ahli bahasa digunakan untuk mengetahui apakah hasil terjemahan dari mesin penerjemah statistik mendekati atau bahkan sudah sesuai dengan terjemahan dari ahli bahasa dapat dilihat pada Gambar. 15.

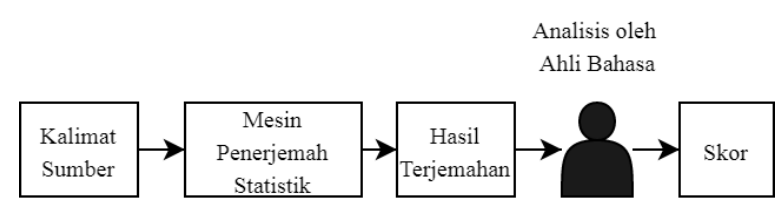

Gambar. 15. Proses evaluasi secara manual oleh ahli bahasa [2]

\section{H. Analisis Hasil Pengujian}

Analisis hasil pengujian dilakukan untuk menentukan algoritma smoothing mana yang paling tinggi nilai akurasi terjemahannya pada jenis language model toolkit IRSTLM serta faktor yang mempengaruhi mengapa akurasi algoritma tersebut dapat memiliki akurasi yang terbaik berdasarkan kesetaraan penambahan jumlah korpus pada setiap mesin secara konstan, nilai yang dihasilkan pada percobaan yang terakhir akan dilakukan perbandingan sehingga didapatkan nilai tertinggi dari algoritma smoothing yang digunakan. Setelah didapatkan nilai tertinggi dari algoritma yang digunakan maka dilakukan metode $K$-fold Cross Validation untuk melihat nilai ratarata akurasi dari keseluruhan korpus yang digunakan, dengan algoritma dan jumlah penggunaan $N$-gram pada mesin penerjemah.

\section{Penarikan Kesimpulan}

Penarikan kesimpulan dilakukan dengan melihat hasil analisis yang dilakukan dari hasil perbandingan nilai akurasi mesin penerjemah statistik dengan algoritma smoothing yang digunakan, dilihat mana algoritma smoothing yang menghasilkan nilai akurasi terbaik. 


\section{HASIL DAN PEMBAHASAN}

Pengujian dilakukan dengan 2 cara yaitu pengujian secara otomatis oleh BLEU dan secara manual oleh Pakar Bahasa dimana dapa dilihat skenario pengujian pada Tabel 1.

TABEL I

SKENARIO PENGUJIAN

\begin{tabular}{|c|c|c|}
\hline No. & $\begin{array}{l}\text { Nama } \\
\text { Pengujian }\end{array}$ & Penjelasan \\
\hline 1 & $\begin{array}{l}\text { Pengujian } \\
\text { otomatis oleh } \\
\text { BLEU }\end{array}$ & $\begin{array}{l}\text { Pengujian ini dilakukan dengan melakukan } \\
\text { penambahan secara konsisten yaitu } 200 \\
\text { kalimat korpus dimana korpus training } \\
\text { pertama berjumlah } 900 \text { kalimat korpus } \\
\text { sampai pada pengujian ke-10 dengan jumlah } \\
\text { kalimat korpus yaitu } 2700 \text { kalimat korpus } \\
\text { dan jumlah korpus uji yang digunakan } \\
\text { sebanyak } 100 \text { kalimat, untuk mengetahui } \\
\text { algoritma smoothing dan mana yang } \\
\text { memiliki nilai akurasi tertinggi pada } \\
\text { language model toolkit IRSTLM. }\end{array}$ \\
\hline 2 & $\begin{array}{l}\text { Pengujian } \\
\text { dengan } \\
\text { Metode } K \text { - } \\
\text { Fold Cross } \\
\text { Validation } \\
\text { dengan data } \\
2700 \text { kalimat } \\
\text { korpus. }\end{array}$ & $\begin{array}{l}\text { Setelah dilakukan pengujian otomatis oleh } \\
\text { BLEU dilihat pengujian keberapa yang nilai } \\
\text { peningkatan BLEU scorenya cenderung } \\
\text { stabil, selanjutnya diambil nilai akurasi } \\
\text { tertinggi dari kombinasi Algoritma } \\
\text { smoothing dan N-gram, dimana BLEU score } \\
\text { tertinggi dari kombinasi algoritma } \\
\text { smoothing dan n-gram dijadikan sebagai } \\
\text { bahan uji. Data uji akan di bagi menjadi } 10 \\
\text { percobaan dari jumlah korpus yang } \\
\text { digunakan yaitu } 2700 \text {, sehingga korpus uji } \\
\text { yang digunakan sebanyak } 270 \text { kalimat. } \\
\text { Tujuan dari pengujian ini yaitu untuk } \\
\text { mencari BLEU score tertinggi berdasarkan } \\
\text { jumlah percobaan pengujian. }\end{array}$ \\
\hline 3 & $\begin{array}{l}\text { Pengujian } \\
\text { dengan } \\
\text { metode } K \text { - } \\
\text { Fold Cross } \\
\text { Validation } \\
\text { dengan data } \\
270 \text { kalimat } \\
\text { korpus. }\end{array}$ & $\begin{array}{l}\text { Berdasarkan hasil yang didapat dari } \\
\text { pengujian dengan metode K-Fold Cross } \\
\text { Validation sebelumnya didapatkan hasil dari } \\
\text { pengujian iterasi ke-2 yang telah dilakukan } \\
\text { dengan metode yang sama. Data uji akan di } \\
\text { bagi menjadi } 10 \text { percobaan dari jumlah } \\
\text { korpus yang digunakan yaitu } 270 \text {, sehingga } \\
\text { korpus uji yang digunakan sebanyak } 27 \\
\text { kalimat. Kemudian nilai pengujian dengan } \\
\text { akurasi tertinggi yang akan digunakan } \\
\text { sebagai korpus uji untuk pengujian manual } \\
\text { oleh ahli bahasa. }\end{array}$ \\
\hline 4 & $\begin{array}{l}\text { Pengujian } \\
\text { manual oleh } \\
\text { Ahli Bahasa }\end{array}$ & $\begin{array}{l}\text { Pengujian ini bertujuan untuk memastikan } \\
\text { secara manual kata per kata dari } 27 \text { kalimat } \\
\text { korpus uji yang sudah didapatkan dari } \\
\text { pengujian sebelumnya, sehingga persentase } \\
\text { pengujian manual didapat dari jumlah kata } \\
\text { yang tepat menurut ahli bahasa dibagi } \\
\text { dengan jumlah kata yang diterjemahkan oleh } \\
\text { mesin. }\end{array}$ \\
\hline
\end{tabular}

Pada pengujian otomatis oleh BLEU disini menggunakan metode penambahan secara konsisten dengan jumlah 200 korpus training yang dimana 100 korpus sebagai korpus uji dan 900 korpus training pada uji pertama, uji kedua sampai uji kesepuluh dilakukan penambahan korpus yang dimana untuk nilai tertinggi pada uji terakhir adalah Modified Kneser-Ney dengan nilai skor BLEU 68,04 pada pengujian 3 gram dan untuk pengujian 5 gram dengan nilai skor BLEU 67,8 yang dapat dilihat pada Tabel 2 dan Tabel 3.
TABEL III

HASIL PENGUJIAN BLEU DENGAN 3 GRAM

\begin{tabular}{|l|l|l|l|l|l|}
\hline \multirow{2}{*}{ No } & \multirow{2}{*}{$\begin{array}{l}\text { Kumlah } \\
\text { Korpus }\end{array}$} & $\begin{array}{l}\text { Back } \\
\text { Off }\end{array}$ & $\begin{array}{l}\text { Witte } \\
\text { n-Bell }\end{array}$ & $\begin{array}{l}\text { Kneser- } \\
\text { Ney }\end{array}$ & $\begin{array}{l}\text { Modified } \\
\text { Kneser- } \\
\text { Ney }\end{array}$ \\
\hline 1 & 900 & 67,46 & 68,36 & 70,91 & 71,81 \\
\hline 2 & 1100 & 66,4 & 67,15 & 70,02 & 70,6 \\
\hline 3 & 1300 & 63,75 & 65,51 & 68,8 & 70,03 \\
\hline 4 & 1500 & 64,42 & 65,48 & 68,45 & 69,23 \\
\hline 5 & 1700 & 62,77 & 64,32 & 67,27 & 67,84 \\
\hline 6 & 1900 & 61,46 & 62,91 & 67,28 & 68,1 \\
\hline 7 & 2100 & 60,96 & 61,94 & 66,2 & 66,78 \\
\hline 8 & 2300 & 62,24 & 63,45 & 67,77 & 68,67 \\
\hline 9 & 2500 & 62,12 & 63,13 & 66,57 & 67,36 \\
\hline 10 & 2700 & 62,3 & 63,58 & 66,74 & $\mathbf{6 8 , 0 4}$ \\
\hline
\end{tabular}

TABEL IIIII

HASIL PENGUJIAN BLEU DENGAN 5 GRAM

\begin{tabular}{|c|c|c|c|c|c|}
\hline \multirow[b]{2}{*}{ No } & \multirow[b]{2}{*}{$\begin{array}{l}\text { Jumlah } \\
\text { Korpus }\end{array}$} & \multicolumn{4}{|c|}{ Algoritma Smoothing } \\
\hline & & $\begin{array}{l}\text { Back } \\
\text { Off }\end{array}$ & $\begin{array}{l}\text { Witte } \\
\text { n-Bell }\end{array}$ & $\begin{array}{l}\text { Kneser- } \\
\text { Ney }\end{array}$ & $\begin{array}{l}\text { Modified } \\
\text { Kneser- } \\
\text { Ney }\end{array}$ \\
\hline 1 & 900 & 68,11 & 69,39 & 70,87 & 71,34 \\
\hline 2 & 1100 & 67,61 & 68,16 & 70,48 & 71,17 \\
\hline 3 & 1300 & 64,81 & 66,25 & 68,59 & 69,75 \\
\hline 4 & 1500 & 64,98 & 66,13 & 68,36 & 69,3 \\
\hline 5 & 1700 & 63,34 & 64,96 & 67,35 & 67,36 \\
\hline 6 & 1900 & 62,97 & 64,09 & 67,18 & 67,82 \\
\hline 7 & 2100 & 61,66 & 63,73 & 66,38 & 67,13 \\
\hline 8 & 2300 & 63,17 & 65,46 & 68,21 & 68,68 \\
\hline 9 & 2500 & 63,15 & 64,47 & 66,75 & 67,53 \\
\hline 10 & 2700 & 63,09 & 64,33 & 66,95 & 67,8 \\
\hline
\end{tabular}

Berdasarkan junal yang berjudul "IRSTLM Toolkit" yang ditulis oleh Macello Federico [16] dinyatakan bahwa Algoritma Smoothing Interpolasi yang dipadukan dengan Modified Kneser-Ney dibawah kondisi training yang tepat dapat menghasilkan nilai perplexity dan BLEU score terbaik ini terbukti pada tabel II dan tabel III. Setelah ditemukannya hasil dengan nilai tertinggi pada Algoritma Smoothing Modified Kneser-Ney dengan 3gram, hasil tersebut yang akan digunakan pada k-fold cross validation, untuk mengetahui iterasi dengan nilai tertinggi dari algoritma smoothing tersebut, adapun nilai yang diperoleh dari pengujian menggunakan metode $k$-fold cross validation dapat dilihat pada Tabel 4. 
TABEL IVV

Hasil Pengujian Metode K-FOLD CROSS VALIDATION DATA Uji 2700

\begin{tabular}{|l|l|c|}
\hline Uji & Data Uji & Indonesia - Sambas \\
\hline 1 & $1-270$ & $\mathbf{6 7 , 8 3}$ \\
\hline 2 & $271-540$ & 67,78 \\
\hline 3 & $541-810$ & 66,15 \\
\hline 4 & $811-1.080$ & 56,67 \\
\hline 5 & $1.081-1.350$ & 45,57 \\
\hline 6 & $1.351-1.620$ & 52,83 \\
\hline 7 & $1.621-1.890$ & 54,97 \\
\hline 8 & $1.891-2.160$ & 51,61 \\
\hline 9 & $2.161-2.430$ & 59,01 \\
\hline 10 & $2.431-2.700$ & 67,44 \\
\hline
\end{tabular}

Pengujian manual dilakukan oleh ahli bahasa Melayu Sambas, pengujian manual diambil berdasarkan hasil pengujian otomatis menggunakan metode $k$-fold cross validation dimana dari hasil pengujian sebanyak 10 kali diambil nilai dengan hasil tertinggi. Adapun nilai tertinggi didapat pada uji pertama dengan korpus uji kalimat 1 sampai 270 dengan nilai 67,83\%. Setelah didapatkan nilai tertiggi maka pada data uji dengan nilai tertinggi itu dilakukan lagi pengujian sebanyak 10 kali uji menggunakan metode $k$-fold cross validation dengan pembagian data uji seperti terlihat pada Tabel 5.

TABEL V

Hasil Pengujian Metode K-Fold CRoss VALIDATION DAta Uji 270

\begin{tabular}{|l|l|c|}
\hline $\mathbf{U j i}$ & Data Uji & Indonesia - Sambas \\
\hline 1 & $1-27$ & 77,93 \\
\hline 2 & $27-54$ & 76,35 \\
\hline 3 & $55-81$ & 78,87 \\
\hline 4 & $82-108$ & 76,27 \\
\hline 5 & $109-135$ & 84,18 \\
\hline 6 & $136-162$ & 67,17 \\
\hline 7 & $163-189$ & 78,24 \\
\hline 8 & $190-216$ & 77,77 \\
\hline 9 & $217-243$ & 82,84 \\
\hline 10 & $244-270$ & 78,84 \\
\hline
\end{tabular}

Setelah didapatkan hasil dari pengujian diatas pengujian dengan nilai tertinggi akan digunakan sebagai data untuk dilakukan pengujian manual oleh ahli bahasa yang dimana terlihat pada pengujian kelima dengan nilai $84,18 \%$ dari data ini nanti akan dihitung persentase akurasi yang dihasilkan pada pengujian manual dengan persamaan :

$$
\mathrm{P}=\frac{C}{R} \times 100 \%
$$

$\mathrm{P}=$ Persentase akurasi

$\mathrm{C}=$ Jumlah kata yang diterjemahkan dengan tepat menurut penilaian dari ahli bahasa

$\mathrm{R}=$ Jumlah kata hasil terjemahan

TABEL VI

Hasil Pengujian Manual oleh Ahli Bahasa

\begin{tabular}{|l|l|l|l|c|}
\hline No. & $\begin{array}{l}\text { Nama Ahli Bahasa } \\
\text { Melayu Sambas }\end{array}$ & $\mathbf{C}$ & $\mathbf{R}$ & $\begin{array}{l}\text { P=C/R*100 } \\
\text { \% }\end{array}$ \\
\hline 1. & Sandra, S.Pd & 866 & 896 & $96,65 \%$ \\
\hline 2. & Hary, S.Pd & 850 & 896 & $94,87 \%$ \\
\hline
\end{tabular}

\section{KESIMPULAN}

Berdasarkan hasil analisis dan pengujian yang sudah dilakukan dapat diambil kesimpulan sebagai berikut.

1. Berdasarkan pengujian dengan metode penambahan korpus secara konsisten algoritma smoothing terbaik adalah modified kneser-ney menggunakan 3 gram dengan nilai akurasi $68,04 \%$ dan algoritma smoothing modified kneser-ney menggunakan 5 gram dengan nilai akurasi $67,8 \%$.

2. Pada penelitian yang telah dilakukan dengan menggunakan korpus sebanyak 2700 buah dengan penambahan korpus secara konsisten yang dimulai dari 900 korpus dihasilkan akurasi terbaik dengan nilai $68,04 \%$ oleh algoritma smoothing modified kneser-ney dengan 3 gram, dan 67,8\% pada algoritma smoothing modified kneser-ney dengan 5 gram dimana hal ini sesuai dengan apa yang disampaikan oleh Marcello Federico dalam jurnalnya.

3. Penilaian oleh Ahli Bahasa berbanding lurus dengan hasil terbaik dari pengujian dengan metode $K$-Fold Cross Validation dikarenakan nilai dari hasil uji terbaik pengujian manual oleh mesin penerjemah statistik adalah sebesar $84,18 \%$ dan hasil pengujian manual mendekati $100 \%$ yaitu pengujian oleh Sandra,S.Pd sebesar 96,65\%, Hary, S.Pd sebesar $94,87 \%$ hal ini menunjukkan bahwa kualitas penerjemahan manual juga sama baik dengan penerjemahan oleh mesin.

\section{REFERENSI}

[1] F. Lafamane, "Fenomena Penggunaan Bahasa Daerah di Kalangan Remaja. PBB ( Unesco : United Nations Education, Social and Culture Organization )," 2020.

[2] I. Hadi, "Uji Akurasi Mesin Penerjemah Statistik (MPS) Bahasa Indonesia ke Bahasa Melayu Sambas dan Mesin Penerjemah Statistik (MPS) Bahasa Melayu Sambas ke Bahasa Indonesia," J. Sist. dan Teknol. Inf., vol. 2, no. 3, 2014.

[3] A. Godase and S. Govilkar, "MACHINE TRANSLATION DEVELOPMENT FOR INDIAN LANGUAGES AND ITS APPROACHES," vol. 4, no. 2, pp. 55-74, 2015.

[4] Y. Solomon, M. Meshesha, and W. Endale, "Optimal Alignment For Bi-Directional Afaan Oromo-English Statistical Machine Translation," vol. 3, no. 7, pp. 73-77, 2019.

[5] A. Hannan, "Assamese-English Bilingual Machine Translation," Int. J. Nat. Lang. Comput., vol. 3, no. 3, 2014, doi: 10.5121/ijnlc.2014.3307. 
[6] W. Zhang, "Comparing the Effect of Smoothing and N-gram Order: Finding the Best Way to Combine the Smoothing and Order of N-gram," Master Sci. Comput. Eng., 2015.

[7] P. Koehn, Statistical Machine Translation. New York: Cambridge University Press, 2010.

[8] S. F. Chen and J. Goodman, "An Empirical Study of Smoothing Techniques for Language Modeling An Empirical Study of Smoothing Techniques for Language Modeling," Comput. Sci. Gr. Harvard Univ. Rep. TR-10-98, 1998.

[9] M. Federico, N. Bertoldi, M. Cettolo, F. R. Scientifica, V. Sommarive, and P. Tn, "IRSTLM : an Open Source Toolkit for Handling Large Scale Language Models,” pp. 1618-1621, 2008.

[10] A. Paul and B. S. Purkayastha, English to Nepali Statistical Machine Translation System. Springer Singapore, 2018.

[11] R. Kneser and H. Ney, "Improved backing-off for M-gram language modeling," In ICASSP-95, vol. 1, pp. 181-184, 1995.

[12] H. Sujaini, "Peningkatan Akurasi Penerjemah Bahasa Daerah dengan Optimasi Korpus Paralel," J. Nas. Tek. Elektro dan Teknol. Inf., vol. 7, no. 1, 2018.

[13] L. Marlinda and H. Rianto, "Pembelajaran Bahasa Indonesia Berbasis Sain," Manaj. Inform. Jakarta, pp. 181-190, 2013.

[14] G. Lample, A. Conneau, L. Denoyer, and M. Ranzato, "Unsupervised machine translation using monolingual corpora only," arXiv, no. 2011, pp. 1-14, 2017.

[15] H. Sujaini, "Meningkatkan Peran Model Bahasa dalam Mesin Penerjemah Statistik (Studi Kasus Bahasa Indonesia-Dayak Kanayatn)," Khazanah Inform. J. Ilmu Komput. dan Inform., vol. 3, no. 2, p. 51, 2017, doi: $10.23917 /$ khif.v3i2.4398

[16] M. Federico, "IRSTLM Toolkit," FBK-irst, 2010.

[17] D. Jurafsky and J. H. Martin, "Speech and Language Processing," Zeitschrift fur Sprachwiss., vol. 21, no. 1, pp. 134135, 2002, doi: 10.1515/zfsw.2002.21.1.134

[18] S. Islam and B. S. Purkayastha, "English to Bodo Phrase-Based Statistical Machine Translation," Adv. Comput. Commun. Technol. Springer, Singapore, pp. 207-217, 2018.

[19] H. F. Tapikap, B. S. Djahi, T. Widiastuti, J. I. Komputer, U. N. Cendana, and K. C. Validation, "Hanna Florenci Tapikap 1 , Bertha S. Djahi 2, Tiwuk Widiastuti 3 Jurusan Ilmu Komputer, Fakultas Sains dan Teknik, Universitas Nusa Cendana," vol. 7, no. 1, pp. 21-26, 2019. 